\title{
Dy(III) Doped BiOCl Powder with Superior Highly Visible-Light-Driven Photocatalytic Activity for Rhodamine B Photodegradation
}

\author{
Jun Yang ${ }^{1,+}$, Taiping Xie ${ }^{2,3,+}$, Chenglun Liu ${ }^{3,4, *}$ and Longjun $\mathrm{Xu}^{3, *}$ \\ 1 College of Materials and Chemical Englineering, Chongqing University of Arts and Sciences, \\ Yongchuan 402160, China; bbyangjun@foxmail.com \\ 2 Chongqing Key Laboratory of Extraordinary Bond Engineering and Advanced Materials \\ Technology (EBEAM), Yangtze Normal University, Chongqing 408100, China; deartaiping@163.com \\ 3 State Key Laboratory of Coal Mine Disaster Dynamics and Control, Chongqing University, \\ Chongqing 400044, China \\ 4 College of Chemistry and Chemical Engineering, Chongqing University, Chongqing 401331, China \\ * Correspondence: xlclj@cqu.edu.cn (C.L.); xulj@xqu.edu.cn (L.X.) \\ + These authors contributed equally to this work.
}

Received: 15 August 2018; Accepted: 4 September 2018; Published: 6 September 2018

check for updates

\begin{abstract}
Dy-doped BiOCl powder photocatalyst was synthesized A one-step coprecipitation method. The incorporation of $\mathrm{Dy}^{3+}$ replaced partial $\mathrm{Bi}^{3+}$ in $\mathrm{BiOCl}$ crystal lattice system. For Rhodamine $\mathrm{B}$ (RhB) under visible light irradiation, $2 \%$ Dy doped BiOCl possessed highly efficient photocatalytic activity and photodegradation efficiency. The photodegradation ratio of RhB could reach $97.3 \%$ after only $30 \mathrm{~min}$ of photocatalytic reaction; this was more than relative investigations have reported in the last two years. The main reason was that the $4 \mathrm{f}$ electron shell of $\mathrm{Dy}$ in the $\mathrm{BiOCl}$ crystal lattice system can generate a special electronic shell structure that facilitated the transfer of electron from valance band to conduction band and separation of the photoinduced charge carrier. Apart from material preparation, this research is expected to provide important references for RhB photodegradation in practical applications.
\end{abstract}

Keywords: $\mathrm{Dy}^{3+}$; $\mathrm{BiOCl}$; photocatalyst; RhB photodegradation; doping modification

\section{Introduction}

Photocatalytic technology using visible light irradiation is an environmentally-friendly approach towards environmental pollutant treatment. It has attracted considerable attention due to inexhaustible visible light from solar light energy. Over the past few decades, some visible-light-driven photocatalysts were engineered and fabricated for the photodegradation of organic wastewater. For example, $\mathrm{Fe}^{(0)}$ doped g- $\mathrm{C}_{3} \mathrm{~N}_{4} / \mathrm{MoS}_{2}$, fluorinated $\mathrm{Bi}_{2} \mathrm{WO}_{6}$, and $\mathrm{TiO}_{2}$ with interface defects [1-3] were synthesized, specifically aiming at Rhodamine $\mathrm{B}(\mathrm{RhB})$ photodegradation. However, the corresponding photocatalytic reactions were very slow and took several hours to degrade less than $98 \% \mathrm{RhB}$, thus impeding their practical application due to the high time costs. If the used light source was simulated visible light, and not solar light, the long times of the photocatalytic reaction would increase energy consumption and costs. Therefore, the challenges we face are how to enhance photocatalytic reaction kinetics, to shorten reaction time, and to boost photocatalytic efficiency under identical visible light irradiation.

Bi-based photocatalysts are important visible-light-responsive photocatalysts and have recently attracted increasing attention. Considering the stability of $\mathrm{Bi}^{3+}, \mathrm{Bi}^{3+}$-containing compounds, such as $\mathrm{Bi}_{2} \mathrm{O}_{3}, \mathrm{BiVO}_{4}, \mathrm{Bi}_{2} \mathrm{WO}_{6}, \mathrm{BiPO}_{4}, \mathrm{BiFeO}_{3}$, and $\mathrm{BiOX}(\mathrm{X}=\mathrm{Cl}, \mathrm{Br}, \mathrm{I})$ [4], were synthesized for photocatalytic reactions. Most of these compounds, especially $\mathrm{BiOX}(\mathrm{X}=\mathrm{Cl}, \mathrm{Br}, \mathrm{I})$, possessed a layered structure and a 
plate-like appearance that could produce an internal electric field [5,6], which facilitated the migration of photoinduced carriers to some extent. Among these $\mathrm{Bi}^{3+}$-based photocatalysts, studies regarding the structure and properties of $\mathrm{BiOCl}$ were found. In fact, the photogenerated electrons and holes of $\mathrm{BiOCl}$ have not been easily exploited and utilized under visible light irradiation [4,7].

Foreign ion doping has been widely adopted to increase the visible light absorption for single phase photocatalysts, because this process can generate a doping level between the conduction band (CB) and valence band (VB) [8]. Consequently, the energy required to excite electrons is decreased, and the light response of semiconductors is enhanced. Doping modification also steered the charges migrating in a special manner for semiconductors, thus leading to an augmented transfer efficiency of carriers. Hence, doping modifications were commonly employed to boost the photocatalytic activity of Bi-based semiconductors.

Dy-doped $\mathrm{ZnO}$ nanoparticles using a photocatalyst were also investigated [9-11]. This rare earth metal (Dy) was used as an efficient dopant into the interstitial sites of the $\mathrm{ZnO}$ crystal structure. It has been found that rare-earth-metal-doping modification could reduce the electron-hole pair recombination, which is the precondition for efficient photocatalytic applications. Dy could also be incorporated in the crystal lattice of $\mathrm{ZnO}$ and thus form $\mathrm{ZnO}$ nanoparticles, which could be tuned for optical, morphological and photocatalytic properties. $\mathrm{Dy}^{3+}$ ions are well known as an activated dopant for different inorganic crystal lattices, producing visible light by appropriately adjusting yellow and blue emissions.

To the best of our knowledge, no studies have investigated the application of in situ synthesized Dy-doped $\mathrm{BiOCl}$ powder photocatalyst for $\mathrm{RhB}$ photodegradation in aqueous environments. The as-synthesized Dy-doped BiOCl possessed good photocatalytic activity for the removal of RhB. A total of $97.3 \% \mathrm{RhB}$ could be degraded in only $30 \mathrm{~min}$ of photocatalytic reaction under visible light irradiation.

\section{Experimental Section}

All reagents were of analytical grade purity and were used directly without further purification. Deionized water was used in all experimental processes.

\subsection{Materials Syntheses}

One gram of polyvinylpyrrolidone K30 (PVP K30, Aladdin, Shanghai, China) was completely dissolved in $100 \mathrm{~mL}$ distilled water via agitation to form a homogeneous solution that was divided into two parts. A total of $5 \mathrm{mmol} \mathrm{Bi}\left(\mathrm{NO}_{3}\right)_{3} \cdot 5 \mathrm{H}_{2} \mathrm{O}$ (Sigma-Aldrich, Hongkong, China) and a proper mol\% amount of Dy $\left(\mathrm{NO}_{3}\right)_{3} \cdot 6 \mathrm{H}_{2} \mathrm{O}(0.5 \%, 1 \%, 1.5 \%, 2 \%, 2.5 \%)$ (Sigma-Aldrich) were then completely dissolved in the above homogeneous solution by stirring for $30 \mathrm{~min}$. A total of $5 \mathrm{mmol} \mathrm{KCl}$ (JZ Chemical, Taoyuan, Taiwan) was also dissolved in the above homogeneous solution by stirring. Then, $\mathrm{KCl}$ solution was slowly added into $\mathrm{Bi}\left(\mathrm{NO}_{3}\right)_{3} \cdot 5 \mathrm{H}_{2} \mathrm{O}$ and $\mathrm{Dy}\left(\mathrm{NO}_{3}\right)_{3} \cdot 6 \mathrm{H}_{2} \mathrm{O}$ mixed suspension under magnetic stirring conditions, and then continuously stirred for $4 \mathrm{~h}$. The mixed solution was filtered. The obtained filter cake was washed several times using $300 \mathrm{~mL}$ deionized water and $150 \mathrm{~mL}$ absolute ethyl alcohol. The washed filter cake was dried at $80^{\circ} \mathrm{C}$ for $10 \mathrm{~h}$ to obtain the resultant Dy-doped $\mathrm{BiOCl}$. The pure $\mathrm{BiOCl}$ was synthesized using the similar process without adding Dy $\left(\mathrm{NO}_{3}\right)_{3} \cdot 6 \mathrm{H}_{2} \mathrm{O}$.

\subsection{Materials Characterization}

X-ray diffraction (XRD) measurements were conducted using standard powder diffraction procedures. The samples were smear-mounted on a glass slide and analyzed at a scan rate of $4^{\circ}$ (20) $\mathrm{min}^{-1}$ using monochromatic $\mathrm{Cu} \mathrm{K} \alpha$ radiation (MAC Science, MXP18, Tokyo, Japan) at $30 \mathrm{kV}$ and $20 \mathrm{~mA}$. The recorded specific peak intensities and $2 \theta$ values were further identified by a computer database system (JCPDS). The chemical compositions of the samples were determined with an X-ray photoelectron spectra (XPS, Physical Electronic ESCA PHI 1600, Chanhassan, MN, USA) at an excitation energy of $1486.6 \mathrm{eV}$ of $\mathrm{Al} \mathrm{K} \alpha$. The $\mathrm{C} 1 \mathrm{~s}(284.5 \mathrm{eV})$ signal served as a calibration standard for the Bi and Dy species and their spectra over a wide region. XPS signals of the above species 
were recorded with a cylindrical mirror analyzer (CMA). The Raman scattering measurements were performed on $\mathrm{BiDyxOCl}$ powder samples using an INVIA Raman microprobe (Renishaw Instruments, Wotton-under-Edge, England). The microprobe had an excitation source (488 $\mathrm{nm}$ ) that was well equipped with a Peltier cooled charge coupled device detector. The morphology, microstructure, and particle size of the as-prepared samples were characterized by field-emission scanning electron microscopy (FE-SEM) (Hitachi, S-4700 Type II, Tokyo, Japan) with a resolution of $0.1 \mathrm{~nm}$ and using a high-resolution transmission electron microscopy (HR-TEM) (Hitachi H-7500, Honshū, Japan) at $100 \mathrm{kV}$, after dispersing the samples on a carbon film supported on a copper grid. The pore volume and surface area of samples were calculated from the nitrogen adsorption-desorption isotherms measured at $-196{ }^{\circ} \mathrm{C}$ using an ASAP 2010 instrument (micromeritics with surface area deviation of 1\%) (ASAP-2010, Micromeritics, Norcross, GA, USA). The optical properties of samples were examined using an ultraviolet-visible diffuse reflectance spectrophotometer (UV-vis DRS, TU1901, Beijing, China).

\subsection{Photocatalytic Test}

One hundred milligrams of powdered photocatalyst were added to $10.0 \mathrm{mg} \cdot \mathrm{L}^{-1} \mathrm{RhB}$ solution $(100.0 \mathrm{~mL})$. The solution was placed in the dark for $1 \mathrm{~h}$, while stirring $\left(500 \mathrm{r} \cdot \mathrm{min}^{-1}\right)$ to reach to adsorption-desorption equilibrium (See Figure S1). Single wavelength light-emitting diode (LED) visible light $(\lambda=470 \mathrm{~nm}$ ) was used as the visible light source (power $=140 \mathrm{~W}$ ). At given irradiation time intervals, a series of the reaction solution was sampled and the absorption spectrum was measured.

\section{Results and Discussion}

\subsection{Phase Analyses}

Figure 1 displays the XRD crystal diffraction patterns of pure $\mathrm{BiOCl}$ and $\mathrm{Dy}$-doped $\mathrm{BiOCl}$ samples. It can be seen that the diffraction peaks are obviously broadened, indicating that the grain size was smaller, which was due to the size effect of PVP. The smaller grain size contributed to the growth of the final products of smaller particles.

The diffraction peaks of all samples were fully indexed into BiOCl (JCPDS card number: PDF\#06-0248) for the tetragonal system [12]. After the introduction of Dy, the diffraction peak of $\mathrm{BiOCl}$ had no obvious displacement, which was similar to the investigation of Eu-doped BiOCl. Similar phenomena were observed through investigations of $\mathrm{Cu}-, \mathrm{Co}$-, and Fe-doped $\mathrm{BiOCl}$ [13-16]. The $\mathrm{Dy}_{2} \mathrm{O}_{3}$ phase or other impurity peaks were not observed. This was indicated that $\mathrm{Dy}^{3+}$ substituted for $\mathrm{Bi}^{3+}$ in the $\mathrm{BiOCl}$ crystal lattice. The grain sizes of pure $\mathrm{BiOCl}$ and $(0.5 \%, 1 \%, 1.5 \%, 2 \%$ and $2.5 \%)$ Dy-doped $\mathrm{BiOCl}$ were 9.9, 8.5, $8.3,7.8,7.8$, and $7.7 \mathrm{~nm}$, determined via calculation using the Scherrer Equation. It can be seen that, with an increase in the Dy doping amount, the grain size of $\mathrm{BiOCl}$ gradually decreased, which was due to the distortion of the crystal cell structure caused by the larger ionic radius of the $\mathrm{Bi}^{3+}$ ion $\left(\mathrm{r}_{\mathrm{Bi}}{ }^{3+}=1.17 \AA\right)$ in the crystal lattice, substituted by $\mathrm{Dy}^{3+}$ with a smaller ion radius $\left(\mathrm{r}_{\mathrm{Dy}}{ }^{3+}=0.91 \AA\right.$ ).

The Raman spectra of pure $\mathrm{BiOCl}$ and Dy doped $\mathrm{BiOCl}$ samples are depicted in Figure 2. The intensity of the symmetric vibration peaks in the Raman spectrum was stronger than that of the asymmetric vibration peaks. The peak at $143.3 \mathrm{~cm}^{-1}$ in the spectrum was assignable to symmetrical stretching vibration of the $\mathrm{Bi}-\mathrm{Cl}$ bond. The peak at $199.6 \mathrm{~cm}^{-1}$ was ascribable to the symmetric expansion vibration of the $\mathrm{Bi}-\mathrm{Cl}$ bond [17]. In addition, the weak and wide peak at $398.0 \mathrm{~cm}^{-1}$ was attributable to the oxygen atom vibration peak in the $\mathrm{BiOCl}$ system. The asymmetric stretching vibration peak of the Bi-Cl bond should appear at $60.0 \mathrm{~cm}^{-1}$, which was not detected here, because the peak intensity of the asymmetric vibration was too weak. Meanwhile, the Raman peaks of BiOCl at $84.0 \mathrm{~cm}^{-1}$ and the peaks of $\mathrm{BiDy}_{2.0} \mathrm{OCl}$ at $88.3 \mathrm{~cm}^{-1}$ were observed, which was due to the crystal lattice distortion caused by Dy doping into the $\mathrm{BiOCl}$ crystal lattice. With the increase in Dy doping amount, the Raman peak at $199.6 \mathrm{~cm}^{-1}$ gradually moved to a low wave number, which resulted from grain size reduction with the increase in the Dy doping amount. 


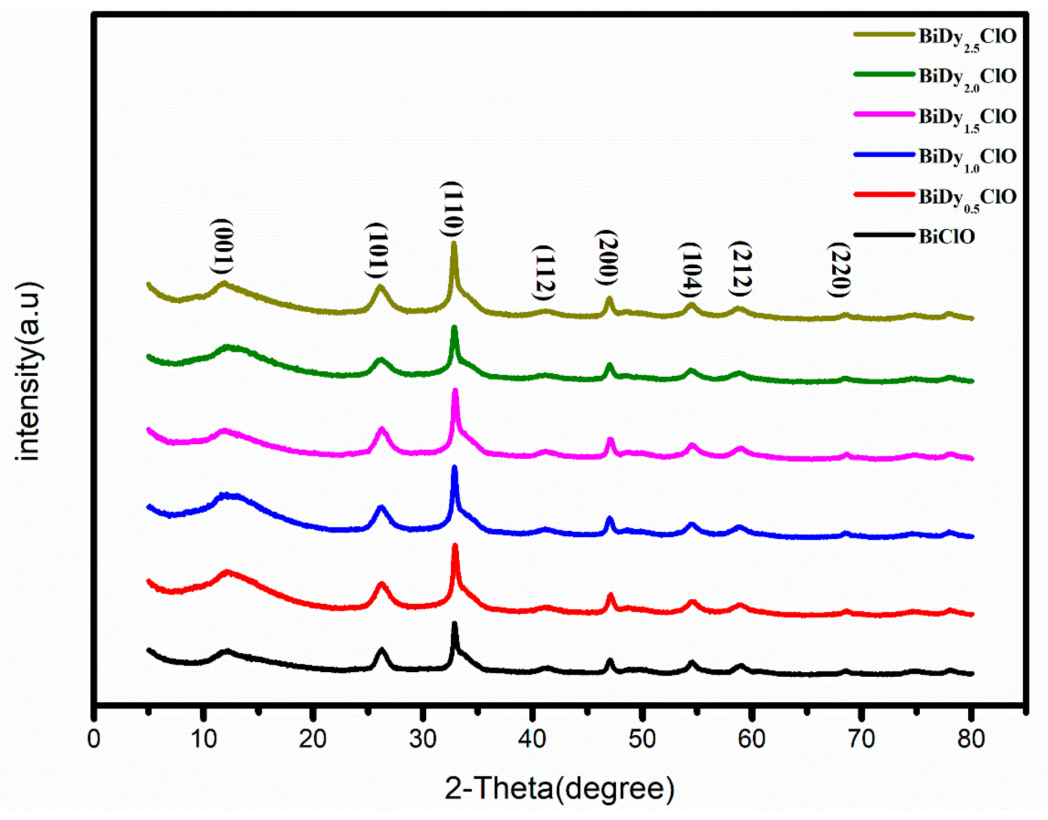

Figure 1. XRD patterns of pure $\mathrm{BiOCl}$ and Dy-doped $\mathrm{BiOCl}$.
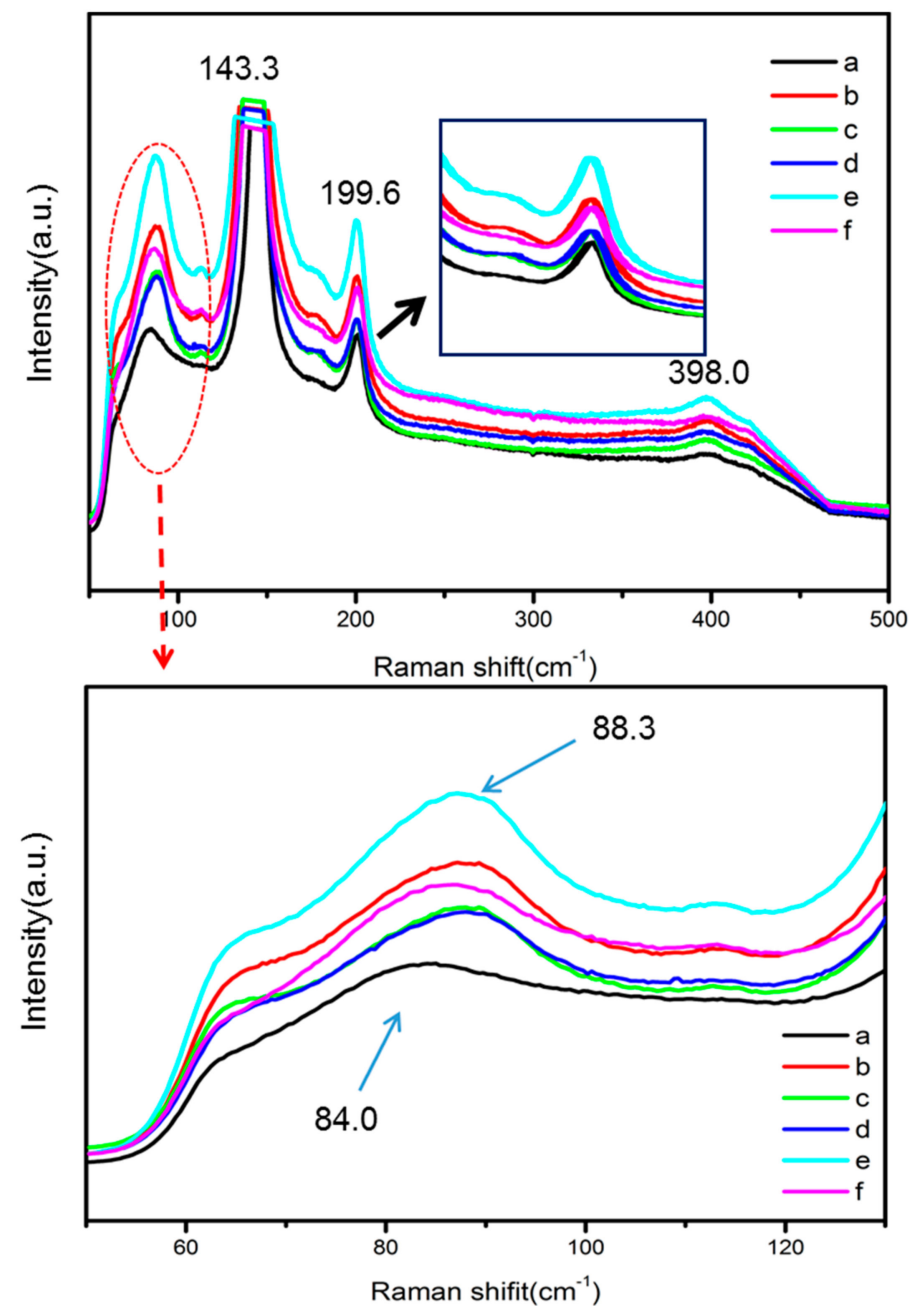

Figure 2. The Raman spectra of (a) $\mathrm{BiClO}$; (b) $\mathrm{BiDy}_{0.5} \mathrm{ClO}$; (c) $\mathrm{BiODy}_{1.0} \mathrm{ClO}$; (d) $\mathrm{BiDy}_{1.5} \mathrm{ClO} ;(\mathbf{e}) \mathrm{BiDy}_{2.0} \mathrm{ClO}$; and (f) $\mathrm{BiDy}_{2.5} \mathrm{ClO}$. 
The surface composition and chemical state of a 2\% Dy-doped BiOCl sample was analyzed by X-ray photoelectron spectroscopy (XPS), as shown in Figure 3. The Dy element was not detected via common or etch methods, which was attributed to the incorporation of Dy entering into the crystal lattice of BiOCl. Figure 3a shows the XPS full spectra of the original sample and the sample with $30 \mathrm{~s}$ of denudation. Only Bi, O, Cl and C were found in the full XPS spectrum of the original sample. The Dy element still could not be detected after etching sample for $30 \mathrm{~s}$. It can be further confirmed that the introduction of $\mathrm{Dy}^{3+}$ replaced $\mathrm{Bi}^{3+}$ in the $\mathrm{BiOCl}$ crystal lattice system.

Figure $3 b-d$ shows the high-resolution spectra of the etching sample. The peaks at $159.09 \mathrm{eV}$ and

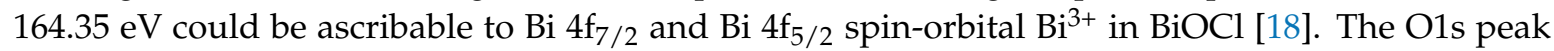
at $532.9 \mathrm{eV}$ was from the oxygen atom of the $\mathrm{Bi}-\mathrm{O}$ bond. The peak of the $\mathrm{Cl} 2 \mathrm{p}$ photoelectron peak appeared at $198.95 \mathrm{eV}$, corresponding to $\mathrm{Cl}^{-}$in $\mathrm{BiOCl}$.
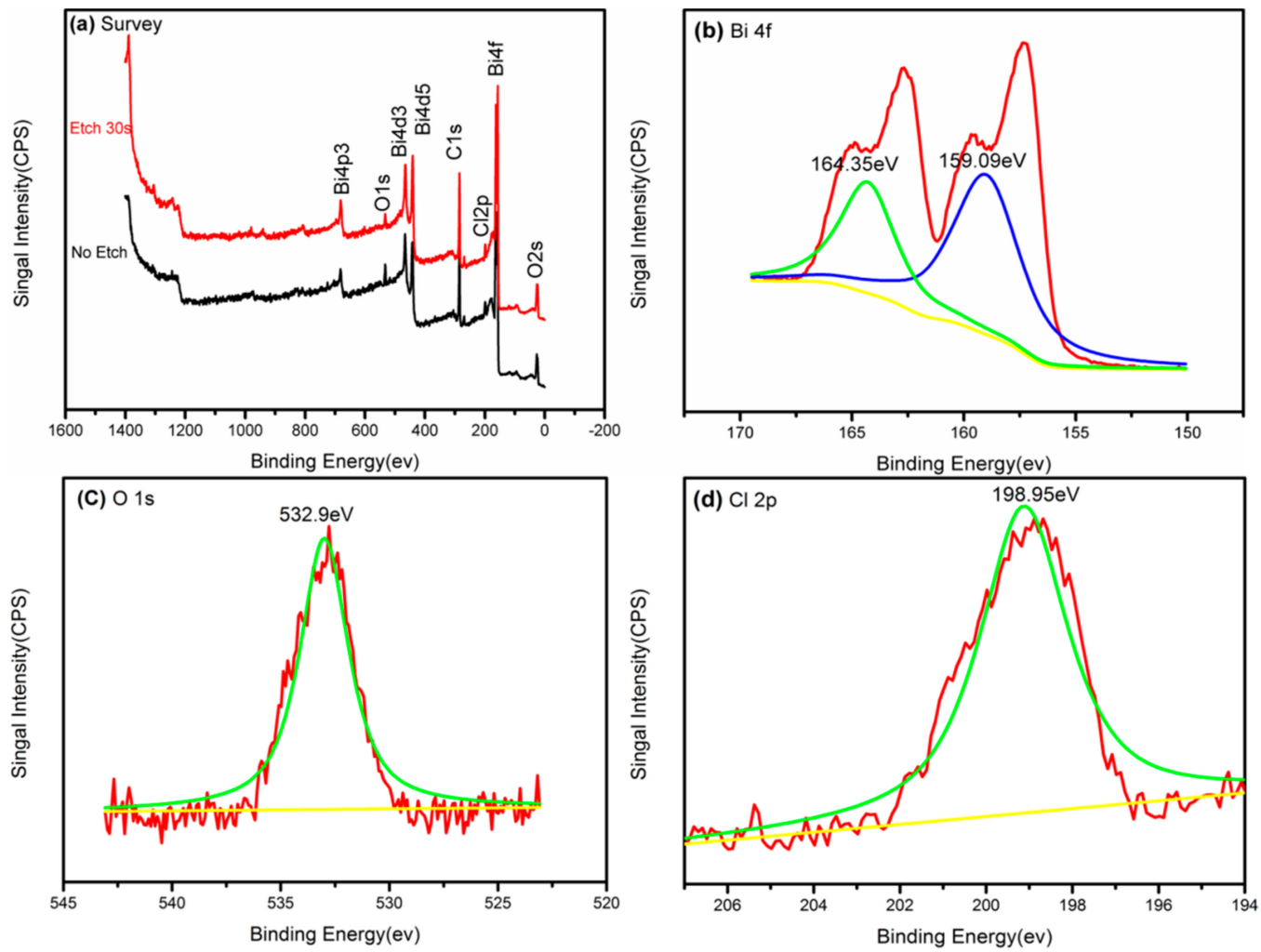

Figure 3. XPS spectra of $2 \%$ Dy doped $\mathrm{BiOCl}$ (a) and the corresponding high-resolution XPS spectra of $\mathrm{Bi}(\mathbf{b}) ; \mathrm{O}(\mathbf{c}) ; \mathrm{Cl}(\mathbf{d})$.

The adsorption-desorption isotherms and the pore size distribution curves (See inset) for pure $\mathrm{BiOCl}$ and $\mathrm{BiDy}_{2.0} \mathrm{OCl}$ are shown in Figure 4. The most probable pore-size distributions were $2.76 \mathrm{~nm}$ and $2.30 \mathrm{~nm}$ for pure $\mathrm{BiOCl}$ and $\mathrm{BiDy}_{2.0} \mathrm{OCl}$, respectively. The introduction of $\mathrm{Dy}$ increased the number of micropore and mesopores, which can be confirmed via the adsorption-desorption isotherms. The BET surface areas for $\mathrm{BiOCl}$ and $\mathrm{BiDy} 2.0 \mathrm{OCl}$ were $4.15 \mathrm{~m}^{2} \cdot \mathrm{g}^{-1}$ and $9.45 \mathrm{~m}^{2} \cdot \mathrm{g}^{-1}$, respectively. Incorporation of Dy could increase the surface area. The smaller ionic radii Dy substituted for Bi could reduce the grain size of $\mathrm{BiOCl}$ and further increase its special surface area. The larger the surface area, the more surface-active sites for a catalyst. 

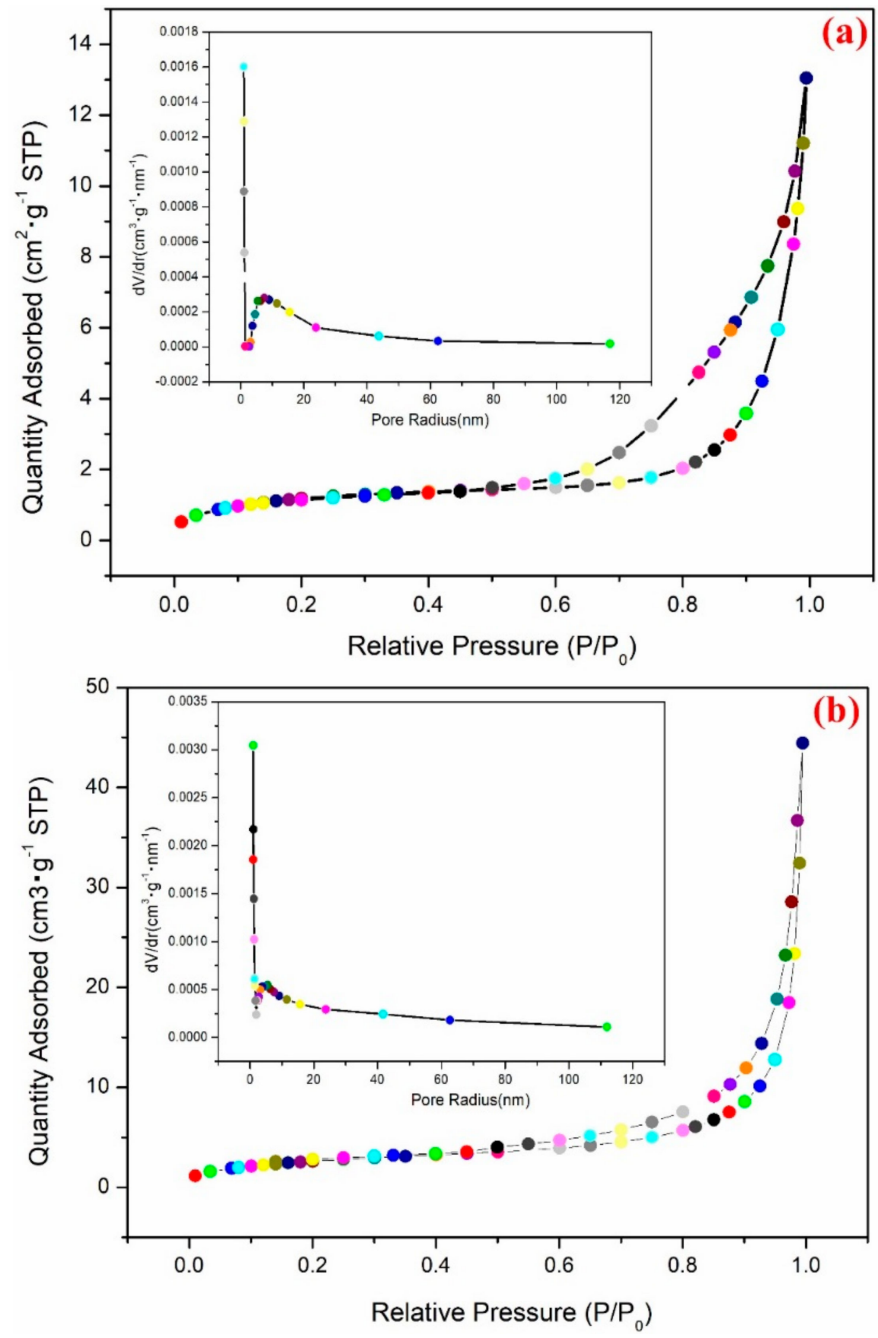

Figure 4. The adsorption-desorption isotherms and the pore size distribution curves (inset). (a) BiOCl and (b) BiDy2.0 $\mathrm{OCl}$.

\subsection{Micromorphology Analyses}

An SEM image of pure BiOCl is shown in Figure 5a. The image presents a spherical-flower structure with a size of $1-2 \mu \mathrm{m}$. With the increase in Dy doping amount from 0.5 to $2.5 \%$, the surface structure remained similar, which revealed that the incorporation of Dy did not change the surface morphology and crystal structure of $\mathrm{BiOCl}$. This further confirmed that $\mathrm{Dy}^{3+}$ entered into the crystal lattice structure of $\mathrm{BiOCl}$.

Figure 6 shows pure $\mathrm{BiOCl}$ and 2\% Dy-doped $\mathrm{BiOCl}$ transmission electron microscope (TEM) diagrams and the corresponding high transmission electron microscope (HR-TEM, Hitachi H-7500, Honshū, Japan) diagrams, which are illustrations of the selected area electron diffraction (SAED). From Figure $5 \mathrm{a}, \mathrm{c}$, it can be seen that the morphologies of pure $\mathrm{BiOCl}$ and $2 \% \mathrm{Dy}$-doped $\mathrm{BiOCl}$ are spherical in structure, which was consistent with the results of the scanning electron microscope test. The results of HRTEM revealed that the crystal lattice stripe was clearly visible and highly consistent, indicating that the crystal structure of the sample was complete and that the crystallinity was good. Further tests indicated that the spacing of the crystal lattice stripe was $0.275 \mathrm{~nm}$ [19] (Figure 6b,d), which corresponded to the space between the (110) surface of the $\mathrm{BiOCl}$ of the tetragonal system, which was also in accordance with the XRD results. Meanwhile, selective electron diffraction of $\mathrm{BiOCl}$ and $2 \%$ Dy-doped BiOCl was carried out. As shown in Figure $6 \mathrm{~b}$,d, clear diffraction points could be observed. The sample belonged to single crystal, corresponding to $\mathrm{BiOCl}$ and $\mathrm{Dy}$-doped $\mathrm{BiOCl}(110)$ and (200) surfaces, respectively, thus indicating that the samples had good crystallinity. 


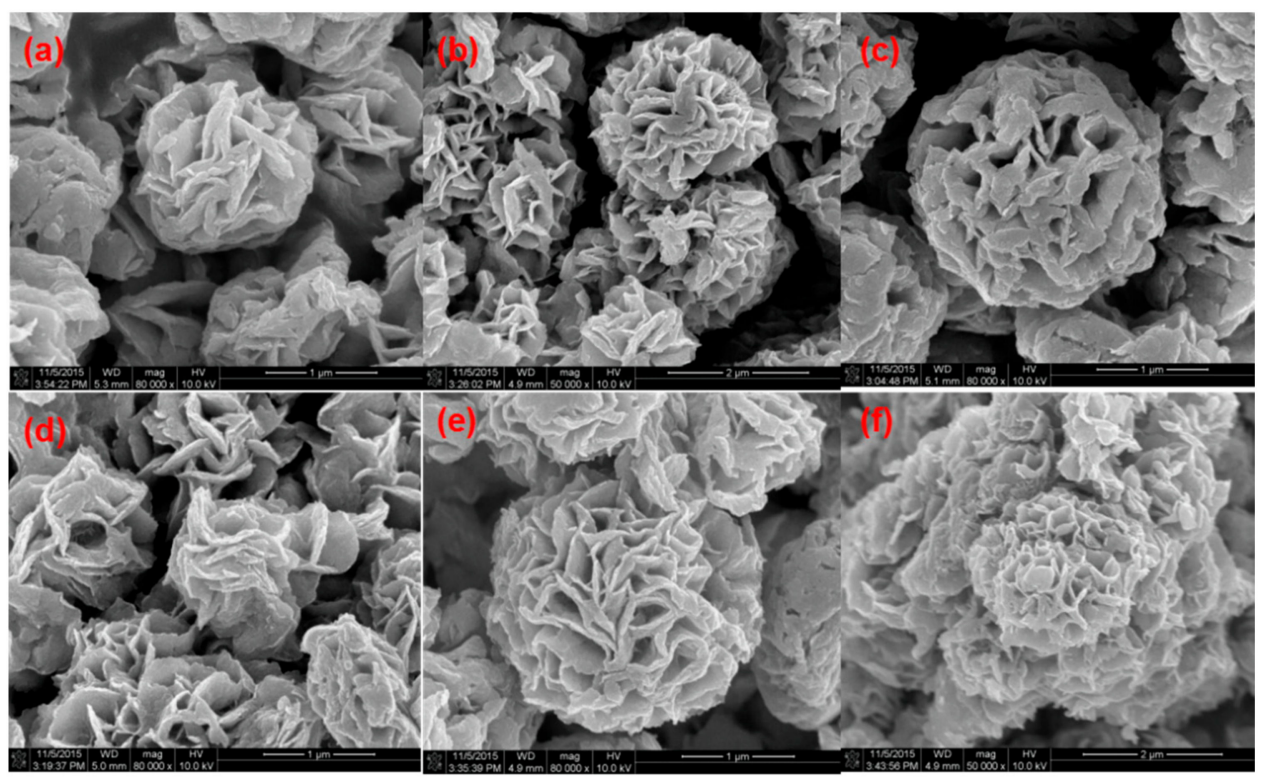

Figure 5. SEM images of $\mathrm{BiOCl}(\mathbf{a})$ and $(0.5 \%, 1 \%, 1.5 \%, 2 \%$ and $2.5 \%)$ Dy-doped $\mathrm{BiOCl}(\mathbf{b}-\mathbf{f})$.

\subsection{Optical Properties}

Figure 7 displays UV-vis diffuse reflectance spectroscopy results and the corresponding band gap energy diagrams of pure $\mathrm{BiOCl}$ and $\mathrm{Dy}$-doped $\mathrm{BiOCl}$.

As can be seen from Figure 7a, with the increase in Dy doping amount, the absorption band of the samples presented a red shift, and the absorption capacity of light increased gradually. Through calculation of the band gap width (Figure $7 \mathrm{~b}$ ), it was found that, when the doping amount was $2.5 \%$, the band gap energy decreased to $3.31 \mathrm{eV}$ from $3.42 \mathrm{eV}$ for pure BiOCl. There was no change in the color of the sample with the introduction of Dy, which implied that Dy showed a change in the electronic structure of the $\mathrm{BiOCl}$, was altered when $\mathrm{Dy}^{3+}$ entered the $\mathrm{BiOCl}$ crystal lattice and replaced $\mathrm{Bi}^{3+}$.

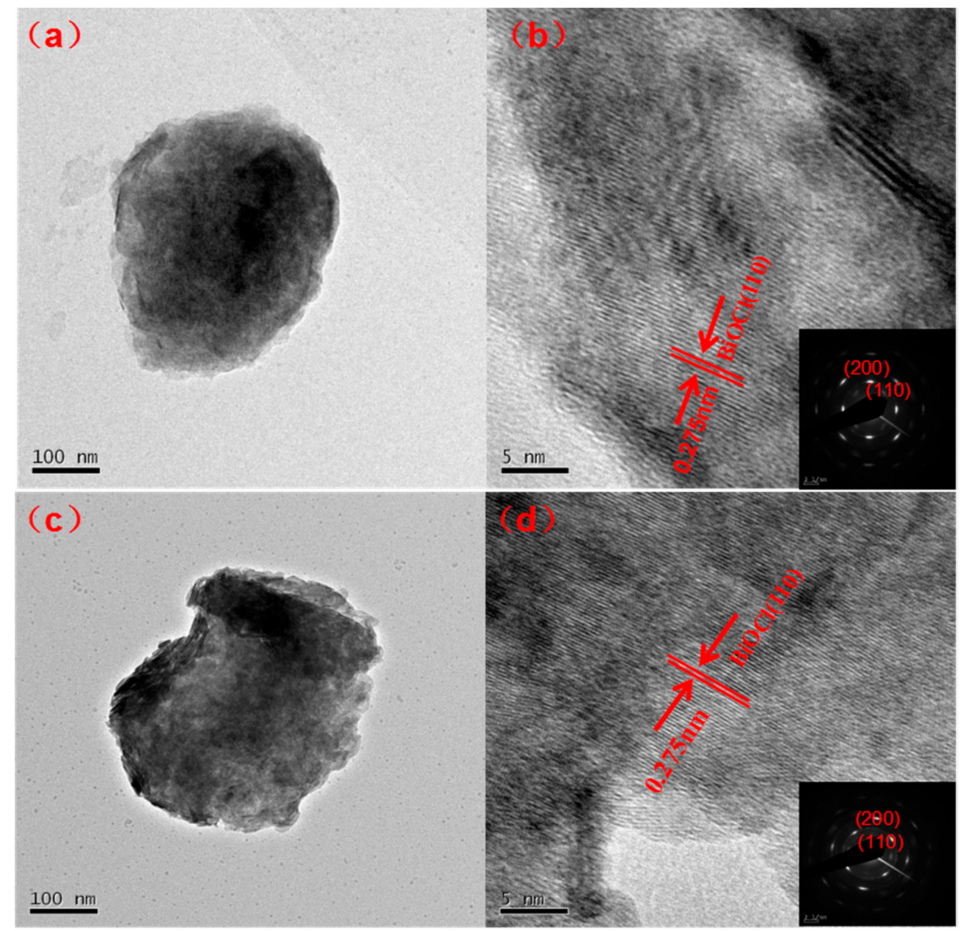

Figure 6. TEM images of $\mathrm{BiOCl}(\mathbf{a}), 2 \%$ Dy doped $\mathrm{BiOCl}$ (c) and corresponding HRTEM (b,d); Inset: SAED pattern of the $\mathrm{BiOCl}$ and $2 \%$ Dy-doped $\mathrm{BiOCl}$. 

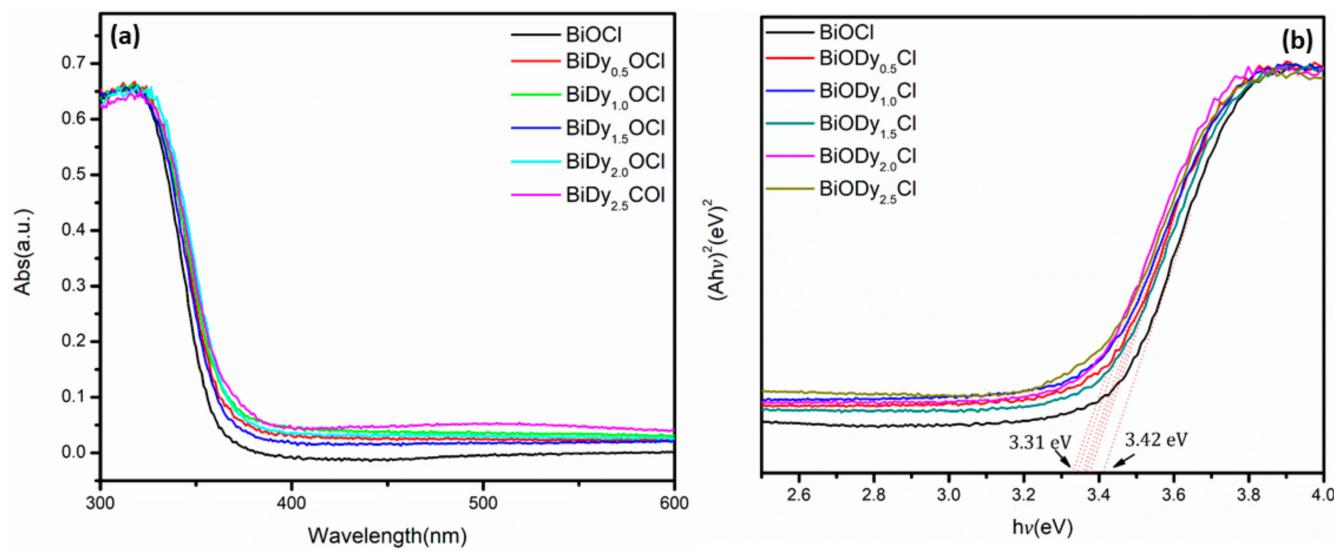

Figure 7. UV-vis diffuses reflectance spectra $\mathrm{BiOCl}$ with different Dy contents (a) and the corresponding band gap energy $(\mathbf{b})$.

The effect of $\mathrm{Mn}$ doping on the electronic structure of $\mathrm{BiOCl}$ was thoroughly studied using the first principle [20]. It was found that $\mathrm{Mn}$ doping could make the whole energy level of $\mathrm{BiOCl}$ move to a low energy level. The incorporation of $\mathrm{Mn}$ was in the middle of the band gap and the bottom of conduction band of the $\mathrm{BiOCl}$ system, which produced a new impurity level, further reducing the width of the band gap.

Rare earth metal elements possess unique optical properties because of their unique electronic structures. The main reason for this is the existence of the $4 \mathrm{f}$ electron shell [21].

The electronic shell structure of rare earth metal elements could be expressed as: $4 \mathrm{f}^{\mathrm{N}} 5 \mathrm{~s}^{2} 5 \mathrm{p}^{6}$. The electron at $4 \mathrm{f}$ shell was not the outermost electron, but indeed the photoactive electrons were at the $4 \mathrm{f} \mathrm{layer} \mathrm{[21].} \mathrm{Therefore,} \mathrm{the} \mathrm{doping} \mathrm{of} \mathrm{rare} \mathrm{earth} \mathrm{metal} \mathrm{ions} \mathrm{would} \mathrm{affect} \mathrm{their} \mathrm{electronic} \mathrm{structure} \mathrm{and}$ change their optical properties. Here, the reduction in band gap energy was attributed to the introduction of $\mathrm{Dy}^{3+}$ ions which could generate a new electron energy level in the middle of the band gap of BiOCl.

The conduction band of $\mathrm{BiOCl}$ was mainly composed of $\mathrm{Bi} 6 \mathrm{p}$, and the valence band was mainly composed of $\mathrm{O} 2 p, \mathrm{Cl} 3 p$ and a small amount of $\mathrm{Bi} 6 \mathrm{~s}$ [22]. Electrons were passed from $\mathrm{O} 2 \mathrm{p}$ and $\mathrm{Cl}$ $3 p$ to the $4 \mathrm{f}$ electronic shell of Dy instead of being directly transmitted to Bi $6 p$, which can be seen in Figure 8. This was a "springboard" between the valence band and the conduction band, which facilitated the easy jump to the conduction band for photoexcited electrons.

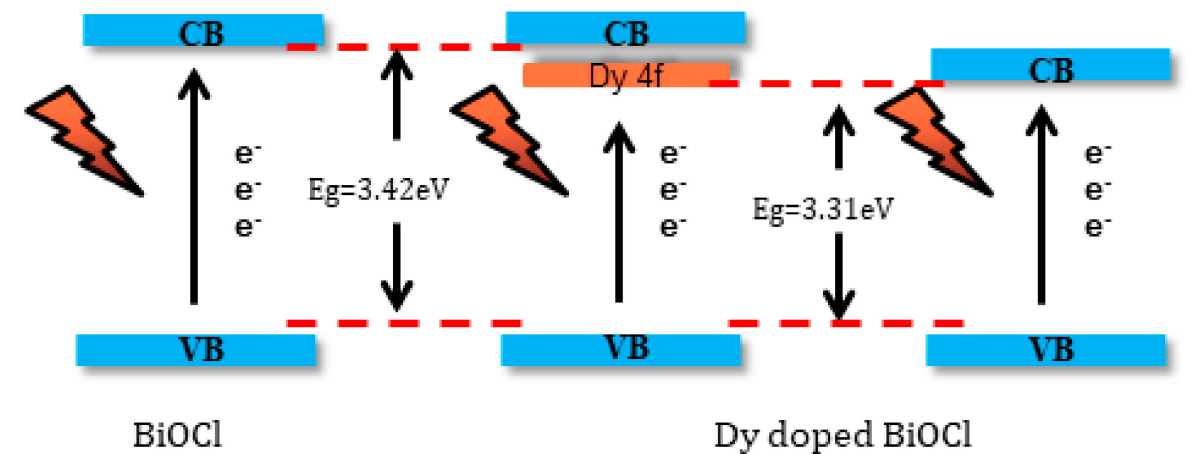

Figure 8. The schematic of reduction in the band gap of $\mathrm{BiOCl}$.

\subsection{Photocatalytic Activity and Corresponding Mechanism}

In order to find the optimal Dy doping amount, the photocatalytic performances of pure $\mathrm{BiOCl}$ and Dy-doped $\mathrm{BiOCl}(0.5 \%, 1 \%, 1.5 \%, 2 \%$ and $2.5 \%)$ samples were investigated via RhB photodegradation under visible light irradiation. This was also the original intention of this modification study for BiOCl. Here, a single wavelength LED light source was used as simulation visible light due to its low light intensity and securing wavelength. The experimental results are shown in Figure 9. 

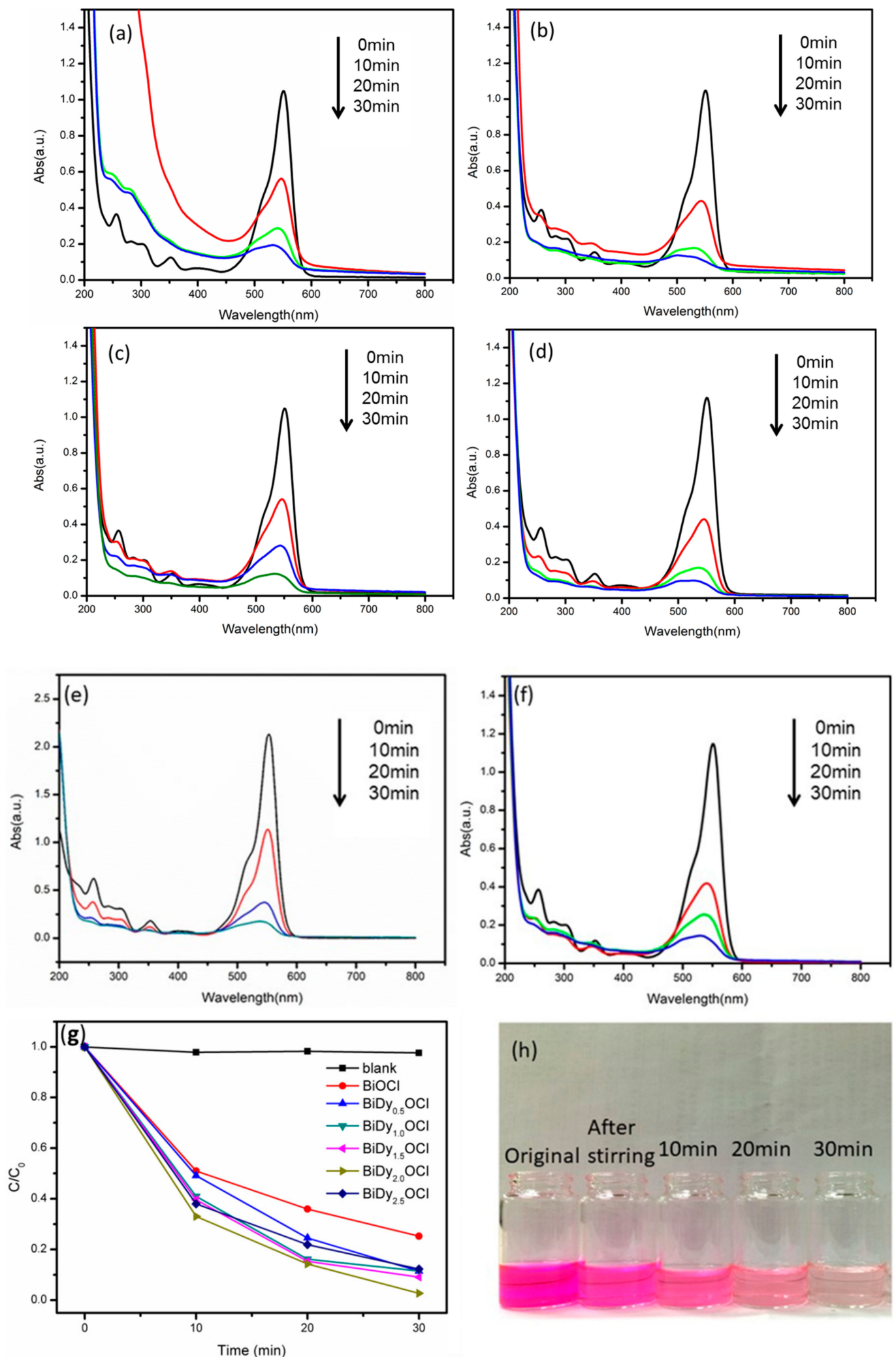

(h)

Figure 9. Time-dependent UV-vis absorption spectra of the RhB in the presence of various Dy-doped $\mathrm{BiOCl}$ photocatalysts $(\mathbf{a}-\mathbf{f})$ and the corresponding degradation ratio of $\mathrm{RhB}(\mathrm{g})$. The color change of $\mathrm{RhB}$ using 2\% Dy doped $\mathrm{BiOCl}$ in photodegradation process (h). 
Figure 9a-f shows the time-dependent UV-vis absorption spectra of RhB in the presence of the as-prepared samples. Figure $9 \mathrm{~g}$, h shows the photocatalytic degradation ratio of RhB versus visible light irradiation time and the color change of $\mathrm{RhB}$ using $2 \% \mathrm{Dy}$-doped $\mathrm{BiOCl}$ as a photocatalyst. It was seen that the $2 \%$ Dy-doped $\mathrm{BiOCl}$ possessed the best photocatalytic activity under identical visible light irradiation. Using 2\% Dy-doped $\mathrm{BiOCl}$, the $\mathrm{RhB}$ photodegradation ratio reached $97.3 \%$, which was 1.3 times more than pure $\mathrm{BiOCl}$ under identical light irradiation (see Table 1). With the increase in the Dy doping amount from 0.5 to $1.5 \%$, photocatalytic efficiency increased tremendously. However, when the Dy doping amount was $2.5 \%$, the $\mathrm{RhB}$ photodegradation ratio decreased, which indicated that excessive Dy doping was detrimental to the enhancement of the photocatalytic activity of $\mathrm{BiOCl}$. In addition, the reaction rate constants were determined from the RhB degradation kinetic curves (Figure 10). The reaction rate constant for $\mathrm{RhB}$ degradation using $2 \% \mathrm{Dy}$-doped $\mathrm{BiOCl}$ as photocatalyst was greatest, ca. $0.084 \mathrm{~min}^{-1}$, which was more than 1.3 times that of pure $\mathrm{BiOCl}$.

Table 1. The photodegradation ratio for $\mathrm{RhB}$ using $\mathrm{BiOCl}$ and $\mathrm{Dy}$ doped $\mathrm{BiOCl}$ samples. A total of $100.0 \mathrm{mg}$ of powder photocatalyst was put into $10.0 \mathrm{mg} \cdot \mathrm{L}^{-1}$ of RhB solution $(100.0 \mathrm{~mL})$.

\begin{tabular}{ccccccc}
\hline Time (min) & BiOCl & BiDy $_{\mathbf{0 . 0 5}} \mathbf{O C l}$ & BiDy $_{\mathbf{0 . 1}} \mathbf{O C l}$ & BiDy $_{\mathbf{0 . 1 5}} \mathbf{O C l}$ & BiDy $_{\mathbf{0} .2} \mathbf{O C l}$ & BiDy $_{\mathbf{0 . 2 5}} \mathbf{O C l}$ \\
\hline 10 & $49.0 \%$ & $51.0 \%$ & $59.0 \%$ & $60.3 \%$ & $67.0 \%$ & $62.0 \%$ \\
20 & $64.0 \%$ & $74.5 \%$ & $83.8 \%$ & $84.7 \%$ & $85.7 \%$ & $78.1 \%$ \\
30 & $74.8 \%$ & $88.6 \%$ & $88.5 \%$ & $90.9 \%$ & $97.3 \%$ & $87.7 \%$ \\
\hline
\end{tabular}

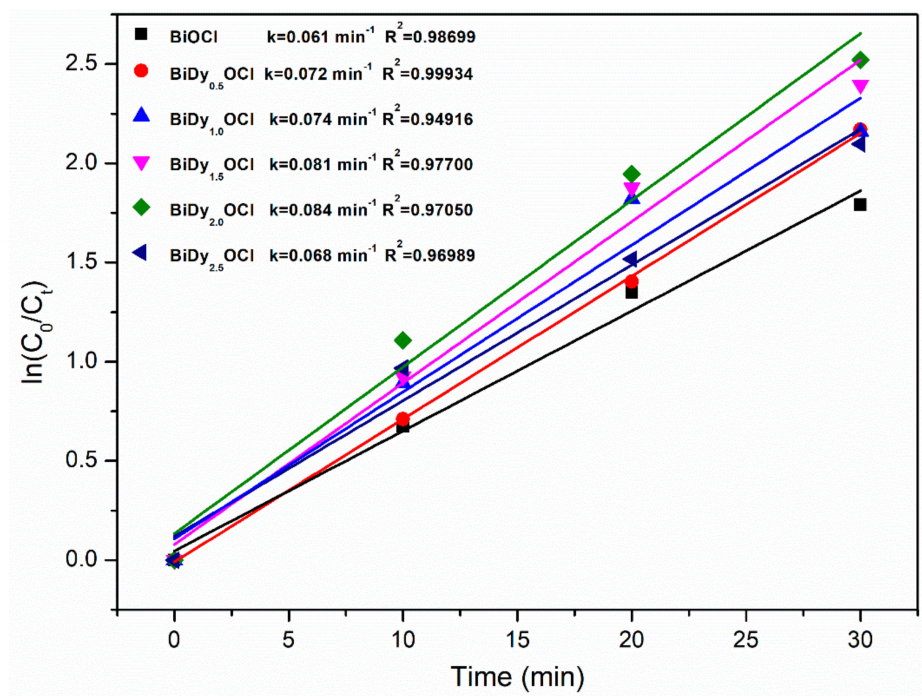

Figure 10. Kinetic linear fitting curve for RhB degradation using different photocatalyst samples.

It is worth mentioning that the photocatalytic activity of $2 \%$ Dy-doped $\mathrm{BiOCl}$ for $\mathrm{RhB}$ photodegradation was outstanding. To the best of our knowledge, the photocatalytic ratio reached $97.3 \%$ after only 30 min of photocatalytic reaction, and the efficiency was superior to that of existing literature reports (see Table S1).

Overall the incorporation of Dy can significantly enhance the photocatalytic activity of $\mathrm{BiOCl}$.

First, the band gap energy of $\mathrm{BiOCl}$ decreased with Dy doping. In addition, the introduction of the $4 \mathrm{f}$ electron shell of Dy was equivalent to adding a "springboard" between the valance band and the covalent band of $\mathrm{BiOCl}$, so that the valence band electrons could be more easily transferred to the conduction band through the 4 f electric sublayer of Dy under visible light irradiation.

Secondly, the electron shell was relatively stable in the semi-full state, and when the Dy ${ }^{3+}$ trapped an electron, the $4 \mathrm{f}$ electron shell in the half-full electron state was destroyed, and the stability was reduced, and the electrons were released to the stable state. The released electrons reacted with the oxygen adsorbed on the surface of the sample to produce a photocatalytic active substance. In fact, a dye sensitized electron was possibly captured by $\mathrm{Dy}^{3+}$, so the $4 \mathrm{f}$ electron shell could be used either as 
an electronic conductor or as a collection of electrons. The two processes could facilitate the separation of photoinduced electron-hole pairs and further improve photocatalytic activity.

Finally, when the Dy doping amount was 2.5\%, the photocatalytic activity decreased. The incorporation of Dy provided a "springboard" for the low energy light activation electron transition, but excessive doping amounts would give rise to scattered distributions for the produced impurity energy, which would generate a recombination center for the electrons and holes.

In fact, environmental pollution resulting from dye wastewater is becoming more and more serious, which prompted humanity to realize the importance of green chemistry (environmentally-friendly chemistry) [23] that advocates for existing chemistry technologies and methods to be used to reduced or stop hazards to human health, community safety and the ecological environment. At present, some reports [24-26] have opened new frontiers in the field of catalysis. A super membrane technology (membrane-grafted catalyst) could reduce the emissions of reaction by-products and the recovery of residual solvents, which would be a good research direction.

\section{Conclusions}

Dy-doped BiOCl powder photocatalyst was synthesized using a one-step coprecipitation method. The incorporation of $\mathrm{Dy}^{3+}$ was successfully substituted for a part of $\mathrm{Bi}^{3+}$ in the $\mathrm{BiOCl}$ crystal lattice system. Two-percent Dy-doped BiOCl possessed the best photocatalytic activity and photodegradation efficiency for RhB under visible light irradiation. The photodegradation ratio of RhB reached $97.3 \%$ within $30 \mathrm{~min}$ of photocatalytic reaction under visible light irradiation. The main reason for this is that the $4 \mathrm{f}$ electron shell of $\mathrm{Dy}$ in the $\mathrm{BiOCl}$ crystal lattice system could generate a special electronic shell structure that facilitated the transfer of electrons from the valance band to the conduction band and also the separation of the photoinduced charge carrier. This work hopes to provide an important reference for RhB photodegradation in practical applications using this photocatalyst.

Supplementary Materials: The following are available online at http:/ /www.mdpi.com/2079-4991/8/9/697/s1, Figure S1: The degradation rate of $\mathrm{RhB}$ with $\mathrm{BiDy}_{2.0} \mathrm{OCl}$ in dark, Table S1: Comparison of photodegradation ratios using different photocatalysts under visible light irradiation (reported in the last two years).

Author Contributions: Supervision, C.L. and L.X.; Funding Acquisition, J.Y. and C.L. In addition, J.Y. and T.X. contributed equally to this work.

Funding: This research was funded by the Chongqing Municipal Education Commission (KJ1711286/KJ1711266) and the Chongqing Basic Science and Advanced Technology Research Program (CSTC2015jcyjBX0015).

Acknowledgments: The authors want to thank the technological guidance of Kuen-Song Lin employed by the Chemical Engineering and Materials Science/Environmental Technology Research Center of Yuan Ze University in Taiwan. We want to thank the financial support from the Scientific and Technological Research Program of the Chongqing Municipal Education Commission (KJ1711286/KJ1711266) and the Chongqing Basic Science and Advanced Technology Research Program (CSTC2015jcyjBX0015). We gratefully acknowledge the many important contributions from the researchers of all the reports cited in this paper.

Conflicts of Interest: The authors declare no conflict of interest.

\section{References}

1. Wang, X.; Hong, M.Z.; Zhang, F.W.; Zhuang, Z.Y.; Yu, Y. Recyclable nanoscale zero valent iron doped $\mathrm{g}_{-} \mathrm{C}_{3} \mathrm{~N}_{4} / \mathrm{MoS}_{2}$ for efficient photocatalytic of $\mathrm{RhB}$ and $\mathrm{Cr}(\mathrm{VI})$ driven by visible light. ACS Sustain. Chem. Eng. 2016, 4, 4055-4063. [CrossRef]

2. Fu, H.B.; Zhang, S.C.; Xu, T.G.; Zhu, Y.F.; Chen, J.M. Photocatalytic degradation of RhB by fluorinated $\mathrm{Bi}_{2} \mathrm{WO}_{6}$ and distributions of the intermediate products. Environ. Sci. Technol. 2008, 42, 2085-2091. [CrossRef] [PubMed]

3. Zhuang, J.D.; Dai, W.X.; Tian, Q.F.; Li, Z.H.; Xie, L.Y.; Wang, J.X.; Liu, P. Photocatalytic degradation of RhB over $\mathrm{TiO}_{2}$ bilayer films: Effect of defects and their location. Langmuir 2010, 26, 9686-9694. [CrossRef] [PubMed]

4. He, R.G.; Xu, D.F.; Cheng, B.; Yu, J.G.; Ho, W.K. Review on nanoscale Bi-based photocatalysts. Nanoscale Horizons 2018. [CrossRef]

5. Jiang, J.; Zhao, K.; Xiao, X.Y.; Zhang, L.Z. Synthesis and facet-dependent photoreactivity of BiOCl single crystalline nanosheets. J. Am. Chem. Soc. 2012, 134, 4473-4476. [CrossRef] [PubMed] 
6. Xie, T.P.; Xu, L.J.; Liu, C.L.; Yang, J.; Wang, M. Magnetic composite BiOCl-SrFe ${ }_{12} \mathrm{O}_{19}$ : A novel p-n type heterojunction with enhanced photocatalytic activity. Dalton Trans. 2014, 43, 2211-2220. [PubMed]

7. Li, H.; Li, J.; Ai, Z.H.; Jia, F.L.; Zhang, L.Z. Oxygen vacancy-mediated photocatalysis of BiOCl: Reactivity, selectivity, and perspectives. Angew. Chem. Int. Ed. 2018, 57, 122-138.

8. Xie, T.P.; Wang, Y.; Liu, C.L.; Xu, L.J. New insights into sensitization mechanism of the Doped Ce (IV) into strontium Titanate. Materials 2018, 11, 646. [CrossRef] [PubMed]

9. Bhatia, S.; Verma, N.; Kumar, R. Morphologically-dependent photocatalytic and gas sensing application of Dy-doped ZnO nanoparticles. J. Alloys Compd. 2017, 726, 1274-1285.

10. Yayapao, O.; Thongtem, T.; Phuruangrat, A.; Thongtem, S. Sonochemical synthesis of Dy-doped ZnO nanostructures and their photocatalytic properties. J. Alloys Compd. 2013, 576, 72-79. [CrossRef]

11. Khataee, A.; Soltani, R.D.C.; Hanifehpour, Y.; Safarpour, M.; Ranjbar, H.G.; Joo, S.W. Synthesis and characterization of dysprosium-doped $\mathrm{ZnO}$ nanoparticles for photocatalysis of a textile dye under visible light irradiation. Ind. Eng. Chem. Res. 2014, 53, 1924-1932. [CrossRef]

12. Gao, X.Y.; Zhang, X.C.; Wang, Y.W.; Peng, S.Q.; Yue, B.; Fan, C.M. Photocatalytic degradation of carbamazepine using hierarchical $\mathrm{BiOCl}$ microspheres: Some key operating parameters, degradation intermediates and reaction pathway. Chem. Eng. J. 2015, 273, 156-165. [CrossRef]

13. Gao, M.C.; Zhang, D.F.; Pu, X.P.; Shao, X.; Li, H.; Lv, D.D. Combustion synthesis and enhancement of BiOCl by doping $\mathrm{Eu}^{3+}$ for photodegradation of organic dye. J. Am. Ceram. Soc. 2016, 99, 881-887. [CrossRef]

14. Zhang, L.; Wang, W.; Sun, S.; Sun, Y.; Gao, E.; Xu, J. Water splitting from dye wastewater: A case study of $\mathrm{BiOCl} /$ copper (II) phthalocyanine composite photocatalyst. Appl. Catal. B 2013, 132, 315-320. [CrossRef]

15. Wang, C.Y.; Zhang, Y.J.; Wang, W.K.; Pei, D.N.; Huang, G.X.; Chen, J.J.; Zhang, X.; Yu, H.Q. Enhanced photocatalytic degradation of bisphenol A by Co doped $\mathrm{BiOCl}$ nanosheets under visible light irradiation. Appl. Catal. B 2018, 221, 320-328. [CrossRef]

16. Huang, C.J.; Hu, J.L.; Cong, S.; Zhao, Z.G.; Qiu, X.Q. Hierarchical BiOCl microflowers with improved visible-light-driven photocatalytic activity by Fe(III) modification. Appl. Catal. B 2015, 174, 105-112. [CrossRef]

17. Li, Y.W.; Zhao, Y.; Wu, G.J.; Ma, H.M.; Zhao, J.Z. Bi superlattice nanopolygons at BiOCl (001) nanosheet assembled architectures for visible-light photocatalysis. Mater. Res. Bull. 2018, 101, 39-47. [CrossRef]

18. Hu, J.L.; Fan, W.J.; Ye, W.Q.; Huang, C.J.; Qiu, X.Q. Insights into the photosensitivity activity of BiOCl under visible light irradiation. Appl. Catal. B 2014, 158, 182-189. [CrossRef]

19. Yang, Y.; Teng, F.; Kan, Y.D.; Yang, L.M.; Liu, Z.L.; Gu, W.H.; Zhang, A.; Hao, W.Y.; Teng, Y.R. Investigation of the charges separation and transfer behavior of $\mathrm{BiOCl}_{\mathrm{BiF}}$ heterojunction. Appl. Catal. B 2017, 205, 412-420. [CrossRef]

20. Zhang, X.C.; Fan, C.M.; Wang, Y.W.; Wang, Y.F.; Liang, Z.H.; Han, P.D. DFT+U predictions: The effect of oxygen vacancy on the structural, electronic and photocatalytic properties of Mn-doped BiOCl. Comput. Mater. Sci. 2013, 71, 135-145. [CrossRef]

21. Shivakumara, C.; Saraf, R.; Halappa, P. White luminescence in $\mathrm{Dy}^{3+}$ doped BiOCl phosphors and their Judd-Ofelt analysis. Dyes Pigments 2016, 126, 154-164. [CrossRef]

22. Zhang, L.; Han, Z.K.; Wang, W.Z.; Li, X.M.; Su, Y.; Jiang, D.; Lei, X.L.; Sun, S.M. Solar-light-driven pure water splitting with ultrathin BiOCl nanosheets. Chem. Eur. J. 2015, 21, 18089-18094. [CrossRef] [PubMed]

23. Didaskalou, C.; Buyuktiryaki, S.; Kecili, R.; Fonte, C.P.; Szekely, G. Valorisation of agricultural waste with adsorption/nanofiltration hybrid process: From materials to sustainable process design. Green. Chem. 2017, 19, 3116-3125. [CrossRef]

24. Macaskie, L.E.; Mikheenko, I.P.; Omajai, J.B.; Stephen, A.J.; Wood, J. Metallic bionanocatalysts: Potential applications as green catalysts and energy materials. Microb. Biotechnol. 2017, 10, 1171-1180. [CrossRef] [PubMed]

25. Schaepertoens, M.; Didaskalou, C.; Kim, J.F.; Livingston, A.G.; Szekely, G. Solvent recycle with imperfect membranes: A semi-continuous workaround for diafiltration. J. Membr. Sci. 2016, 514, 646-658. [CrossRef]

26. Didaskalou, C.; Kupai, J.; Cseri, L.; Barabas, J.; Vass, E.; Holtzl, T.; Szekely, G. Membrane-grafted asymmetric organocatalyst for an integrated synthesis-separation platform. ACS. Catal. 2018, 8, 7430-7438. [CrossRef]

(C) 2018 by the authors. Licensee MDPI, Basel, Switzerland. This article is an open access article distributed under the terms and conditions of the Creative Commons Attribution (CC BY) license (http:// creativecommons.org/licenses/by/4.0/). 